Koedoe 29: x-y (1986)

\title{
The Kruger National Park - An Introduction
}

\section{S.C.J. JOUBERT}

Joubert, S.C.J., 1986. The Kruger National Park - an introduction. Koedoe 29: 1-11. Pretoria. ISSN 0075-6458.

The salient features of the Kruger National Park, Republic of South Africa, are presented. The natural attributes of the area are discussed, its developmental history as a conservation area presented while an overview is given of managerial strategies, tourism and administration.

Key words: Sabi Game Reserve, Shingwedzi Game Reserve, Kruger National Park, policy, management, research, administration.

S.C.J. Joubert, Department of Research and Information, Kruger National Park, Private Bag X402, Skukuza, 1350.

\section{Introduction}

Over the last eighty or more years the Kruger National Park (KNP) has acquired widespread national and international acclaim. The KNP today comprises some 1948528 hectares. It has a natural diversity and species richness which rivals the best the world has to offer in terrestrial ecosystems. Much of the unspoilt character of the area has been retained and is being perpetuated by an ecosystem-oriented management strategy. It has amenities to accommodate 6200 overnight visitors in 18 rest camps, and is run by an efficient and sophisticated administration. In addition, the KNP has a long and chequered history, and the conservation area was moulded by experiences that have been both romantic and traumatic. Whatever the course history has taken, the one major guiding principle in the management of the KNP has always been the preservation of its abundant and varied natural attributes in their pristine state.

\section{Situation and Natural Attributes}

The KNP is situated along the upper reaches of the Moçambique coastal plain in the Transvaal Lowveld, between latitude $22^{\circ} 25^{\prime}$ to $25^{\circ} 32^{\prime} \mathrm{S}$ and longitude $30^{\circ} 50^{\prime}$ to $32^{\circ} 02^{\prime} \mathrm{E}$. It is elongated with a total length of approximately $320 \mathrm{~km}$ and a mean width of roughly 65 kilometres.

ISSN 0075-6458 = Koedoe 29 (1986) 
The climate is characterised by two distinct seasons, i.e. wet and dry season. The wet, or rainy, season extends from October to March/April and the dry season from April/May to August/September. The wet and dry seasons correspond with the hot summer, when temperatures frequently exceed 40 ${ }^{\circ} \mathrm{C}$, and the milder winter respectively. The overall mean annual rainfall is in the region of $500 \mathrm{~mm}-550 \mathrm{~mm}$ and is highest in the south-western, and lowest in the extreme north-eastern areas ( $c f$. Gertenbach 1980).

The topography of the KNP is generally flat with gently undulating plains. In the east it is bordered by the Lebombo Mountains, while the south-western corner to the west of Malelane and the area north of Punda Maria may be considered mountainous.

Geologically the KNP is divided into two almost equal sections, i.e. predominantly granitic formations in the western half and basalts in the eastern half. The two major formations are divided by a narrow belt of shale and sandstone. The soils, in composition and distribution, reflect the same pattern as the geological formations. In the western half the soils are mainly sandy and light in colour while the soils derived from basalt are dark and high in clay content.

The KNP is drained from west to east by two major river systems i.e. the nKomati System in the south and the Limpopo System in the north. The KNP is dissected by six perennial rivers, i.e. the Crocodile, Sabie, Sand, Olifants, Letaba and Luvuvhu, while the Limpopo River forms part of the northern boundary. Several major tributaries of the rivers also flow through the KNP, a number of which originate within the Kruger National Park. Other natural water resources include pools in seasonal rivers, springs and pans.

The vegetation of the KNP may conveniently be divided into eight major sub-divisions (Van der Schijff 1957). On a finer scale a total of 35 landscape types have been identified on the basis of their floristic composition and abiotic environment (Gertenbach 1983).

The KNP has a particularly rich faunal community. In addition to its rich and varied invertebrate fauna, the following number of species/sub-species of vertebrate fauna have been recorded: freshwater fishes 49 , amphibians 33 , reptiles 112 , birds 493 and small mammals 114 . The KNP is, however, best known for its large variety of large mammals, consisting of 23 species of herbivores and 6 species of carnivores.

\section{The Early Years}

From the time of the nomadic Bushmen and the isolated settlements of the Early Stone Age inhabitants, the area now comprising the KNP has been inhabited by people (Verhoef 1986). Decimating diseases which affected both man and his livestock precluded the establishment of extensive or high-density communities. Rather, archaeological evidence suggests that until half-way through the previous century people and livestock numbers fluctuated considerably, and that the lifestyle of the early inhabitants mainly consisted of hunting and gathering, while any form of agriculture played only a minor role. 
The first Europeans moved into the area towards the late 1830 s/early 1840 s. Initially the occupation of the area was slow due to its inhospitable climate, intolerable diseases and remoteness. However, it soon gained popularity as a favoured hunting ground during the milder winter months, and also as a convenient grazing area to tide herds of livestock over the harsh winters of the adjoining Highveld to the west.

Accessibility to the area largely improved with the establishment of a trading route between Lydenburg and Delagoa Bay (Maputo) during the 1870s. It was not until the 1890 s with the construction of the Selati railway line, that the area became fully accessible to all and sundry.

Developments during the latter half of the previous century led to the insurgence of fortune hunters, traders, farmers, sportsmen/adventurers, construction workers and an assortment of characters who found in these remote Lowveld regions a convenient refuge from the prying eyes of the law. No matter what other consideration brought those early pioneers to the region, they all shared one common interest, i.e. hunting opportunities, freedom of movement offered by the area, and variety and numbers of game. As in so many other areas upon which the zealous bands of hunters had converged, the animal populations of the Lowveld were defenceless against the destructive capacity of high-powered rifles (however primitive they may now appear to have been). By the end of the century the general features of the Lowveld were retained unaffected and intact, though most of the larger animal populations had been severely decimated. Some species such as white rhino Ceratotherium simum, became locally extinct, while for several others extinction was imminent.

After tireless rallying, persuading and negotiating which spanned several years a large tract of land between the Crocodile and Sabie rivers was eventually in 1898 proclaimed as the Government Game Reserve. After reproclamation following the Anglo-Boer War (1899-1902) the Sabi Game Reserve came into being, and extended from the Crocodile to the Olifants River. In 1903 the Shingwedzi Game Reserve was proclaimed, and encompassed a vast expanse between the Letaba and Limpopo rivers. Further additions to these two game reserves included an area to the west of the Sabi Game Reserve, and an area between the Olifants and Letaba rivers which linked the two reserves.

When the Government Game Reserve was first proclaimed, there was no infrastructure or conservation agency which could take responsibility for either law-enforcement or the institution of a conservation policy. The area had legally changed status, but the newly acquired status hardly impressed, or was respected by, the rugged Lowvelders who customarily roamed and hunted in the area. Initially, law enforcement was entrusted to Izak Holtzhausen, a sympathetic policeman stationed at Komatipoort, and later to a second policeman from White River, Paul Bester.

When the first Warden, Col. J. Stevenson-Hamilton, was appointed in 1902 he took control of an area that was a game reserve in little more than merely its name. Whites and blacks freely used the area for whatever purposes suited them best, many animal populations were severely depleted, there was no infrastructure and buildings of any nature were almost entirely restricted to 
those used by the South African Railways during the construction of the Selati railway line or those left by the Steinaecker Horse Regiment who patrolled the southern Lowveld during the Anglo-Boer War.

Stevenson-Hamilton initially settled at Crocodile Bridge, but soon moved his headquarters to Reserve, which was later (in 1932) renamed Skukuza. His highest priority as regards nature conservation was to acquire an efficient white and black staff who could apply effective law enforcement, and have them established in strategic outposts.

Soon after the First World War $(1914-1918)$ the first serious consideration was given to the possibility of changing the status of the game reserves to that of a national park. Initially the concept was foreign and difficult to grasp or accept. However, as with the very concept of nature conservation, the determination of a few far-sighted protagonists eventually succeeded, and in May 1926 the Sabi and Shingwedzi game reserves were united as the Kruger National Park.

At the time of its proclamation the KNP had a few advantages over its predecessors, i.e. respect, if not appreciation for the cause of nature conservation had been gained upon the local populace, and a satisfactory degree of control had been gained over poaching. In addition, a definite conservation philosophy and strategy was emerging from the experiences and observations of the staff. Other than these positive factors the KNP was still grossly under-staffed, in desperate need of funds, without clearly demarcated boundaries, lacking tourist or firebreak roads, and without any tourist amenities or administration.

Today the KNP must certainly be considered one of the top national parks of the world. This may primarily be ascribed to its natural attributes, but also to an efficient administration as may be gleaned from the following overview.

\section{Conservation Philosophy and Wildlife Management}

The first basic problems which Stevenson-Hamilton had to contend with from a wildlife management point of view, were prolonged droughts, means of restoring the numbers of herbivorous animal populations, and veldfires. These three areas, and the approaches adopted towards them, were all to play an important role in moulding the management strategy currently applied in the Kruger National Park. A'short resumé of the development of each will suffice to clarify present attitudes.

\section{Climatic cycles and water provision.}

According to meteorological data and the recollections of 'old-timers' it could be assumed that the Lowveld experienced a period of particularly high rainfall from 1890 - 1895 (Sandenberg 1947). When Stevenson-Hamilton took charge of the Sabi Game Reserve (1902) the area was obviously experiencing low rainfall, and as the water resources of the high rainfall years progressively dried up, he concluded that a process of gradual desiccation had set in. The meagre rainfall records available for Skukuza 
from 1908 to 1913 confirm the below-average rainfall of the early twentieth century. Continuous records do not exist but it is clear that from 1917 to 1925 heavy rains again fell.

From 1919/20 good rainfall records exist for the Kruger National Park. From these data the cyclic nature of the rainfall, with approximately 10 years of generally above average rainfall and an equivalent period of generally below average rainfall, may be clearly deduced (Gertenbach 1980). Considering various sources of information Pienaar (1985) also suggested the possiblity of super-imposed long-term climatic cycles.

The subjection of the Lowveld to periodic droughts, and the sparseness of perennial water resources customarily resulted in large concentrations of animals gathering at isolated waterholes during dry spells while vast tracts of good grazing remained under-utilised in the areas devoid of water. This situation initially gave rise to the institution of a water provision policy. In the subsequent developmental phases of the KNP various other factors also contributed toward the formulation of the water provision policy. The dispersion of animals into adjoining areas where they were subjected to poaching, the later fencing of the KNP and the consequent deprivation of animals of their favoured watering points and, more recently, the gradual desecration of the perennial rivers all played an important role in the water provision programme.

In the management of the KNP the ecological effects of water are duly acknowledged, and as more information became available on the natural migrations of some species and the seasonal (winter/summer) distribution patterns of others, the approach towards the provision of artificial water sources was adapted accordingly. Today the cornerstone of the water provision policy is based on the stabilisation of the perennial water resources and is implemented for the maintenance of diversity and species richness.

2. Manipulation of animal populations.

When the area now comprising the KNP was first proclaimed a nature conservation area, it had been subjected to the annual invasions of numerous hunting parties. In addition, the labour force employed for the construction of the Selati railway line largely lived on venison. In 1896 the rinderpest pan-zootic swept through the area and accounted for the demise of large numbers of susceptible herbivores. Finally, the black people from the dispersed settlements and units of soldiers fighting in the Anglo-Boer War also took their toll. It appears as if most of these groups paid little attention to carnivores but decimated the larger herbivore populations to such an extent that there was an obvious imbalance between predators and prey, and that the populations of several species were reduced to the point of imminent local extinction (Stevenson-Hamilton 1906).

Under these circumstances it was considered desirable that the predator populations be reduced to enable the prey populations to recover. In 1912, and again in 1918, reference was made to the favourable effects on prey populations. Towards the end of the 1920 s carnivore control operations 
were repealed, and it was believed that the equilibrium between predators and prey was restored. In spite of opposition Stevenson-Hamilton staunchly defended his decision to end the carnivore control operations and propagated the view that if carnivores were not allowed to check the growth of prey populations the latter would be reduced by means of epizootics ". . . with consequences impossible to foresee" (StevensonHamilton 1937).

In the late 1940 s limited carnivore control was again applied.

In the 1950 s the exercise was intensified and extended to larger areas of the Kruger National Park. Pienaar (1958) formulated the first official carnivore control policy which limited such action to specified situations, particularly to the protection of rare species. In 1961 carnivore control operations were terminated but reinstated in the mid-1970s to assist in easing population crashes amongst wildebeest and zebra.

Through the years natural fluctuations in the population sizes of carnivores and herbivores were recorded. These fluctuations were regarded by Stevenson-Hamilton $(1937,1944)$ as natural phenomena which concurred with similar fluctuations in the rainfall and environmental conditions.

During the 1960s two important events played an important role in determining management policies, i.e. the inception of regular aerial censuses which enabled a more accurate assessment of population numbers and trends, and the commencement of a period of severe drought which lasted throughout the 1960s. The western boundary of the KNP was also fenced during this period. The protracted drought resulted in progressively diminishing water resources, a concomitant increase in high-density, drought resistant species such as wildebeest Connochaetes gnu, zebra Equus burchelli and impala Aepyceros melampus, as well as consequently progressively larger areas of habitat over-utilisation. At the same time, a steep incline in the numbers of elephants, and accompanying range extension, was recorded.

The pressures of these forces eventually led to the institution of culling operations. Species included were elephant Loxodonta africana, buffalo Syncerus caffer, hippo Hippopotamus amphibius, wildebeest, zebra and impala. The fundamental principle involved in taking this highly controversial step was the maintenance of diversity and species richness by preventing habitat degradation, and safeguarding rare and sensitive species from excessive competition.

During the high rainfall phase in the climatic cycle during the 1970 s a new situation was introduced when the vegetation responded dramatically to the high rainfall and induced a severe decline in the populations of species which had flourished during droughts. New approaches had to be adopted and managerial strategies were primarily aimed at manipulating habitats to suit the demands of the short-grass grazers, and to relieve the declining populations of excessive predator pressure by reinstituting carnivore control (lion Panthera leo, and spotted hyaena Crocuta crocuta) in specified areas. 
The two extreme situations in such rapid succession served as a prime motivation for the institution of an holistic and management orientated monitoring programme. Important principles of relevance to management which crystallised from these experiences included a more clearly defined approach towards an ecosystem orientated research strategy, with the retention of the principle of manipulating those populations not affected by short term climatic changes. The population densities attained artificially high levels due to the confinement in the KNP, and exerted a profound influence on habitats.

\section{Veldburning.}

At the time of proclamation, annual veld fires originating from a variety of mostly unnatural causes, were customary. Stevenson-Hamilton (1912) was strongly opposed to such fires, primarily due to the detrimental effect they had on the woody vegetation. He was also convinced that the woody vegetation of the KNP represented a fire-induced 'secondary forest', derived from a 'primary rain forest'. Attempts were therefore made to gain control over fires. However, it soon proved that protection against fires resulted in an accumulation of heavy loads of combustible material, and that subsequent fires were even more damaging to the vegetation. It was then decided to burn the veld biennially during the late summer (March/April).

In 1947 the National Parks Board of Trustees approved a policy whereby the veld would not be burned more than once every five years, and that burning would take place after the first substantial spring rains $(50 \mathrm{~mm})$. In 1957 a more comprehensive veldburning policy was adopted in which the role of fire as a natural phenomenon was acknowledged. The accepted policy basically provided for a triennial burning programme.

During the 1970 s and early 1980 s several amendments to the policy were made. Currently the role of fire as an ecological factor is accepted, and applied in a simulation of the natural fire regime. In this respect fires are

- applied more frequently during periods of high rainfall (when combustible material accumulates more rapidly) and with longer intervals between fires during droughts. These frequencies were determined in accordance with the incidence of recorded 'natural' fires, i.e. lightning-induced fires.

\section{Approach towards management}

It is clear from this short synopsis of the three major management approaches taken in the KNP that information gathered through the years has systematically and consistently been interpreted with the objective of applying management in an ecosystem-orientated approach. In adopting this approach the guiding principles have been the maintenance of the natural structural and species diversity of the area.

In accordance with this policy it is a primary objective to preserve the dynamic processes of the ecosystems insofar as such processes have not been affected by inevitable disturbances. Management strategies are, therefore, 
devised to retain the natural dynamic processes or to simulate such processes on the basis of minimum interference. In pursuance of this objective an extensive monitoring programme has been formulated to serve as basis for the interpretation of the natural course of events and for the determination of management priorities.

\section{Other Management Strategies}

Subject to the primary objectives in the management of the KNP, various complementary management strategies have been applied. These included the reintroduction of species to areas where they had become extinct, the control and extermination of exotics - in particular alien invasive biota, and disease control where such diseases have been transmitted to the KNP ecosystems from other areas, and the diseases pose a threat to the indigenous biota. An example of this form of management is the annual inoculation of roan antelope Hippotragus equinus, against anthrax.

\section{Tourism}

Tourism in the KNP commenced in 1923 with the institution of 'round-in-nine' railway excursions to the Lowveld, and the inclusion of the Sabi Game Reserve in these excursions. It was not, however, until the proclamation of the KNP in 1926 that serious consideration was given to tourism. In 1927 the first motor vehicles were allowed in the Pretoriuskop area but by 1930 rest camps and roads were available to as far north as Letaba.

Initially the National Parks Board of Trustees provided accommodation, i.e. huts and cottage tents, while accessories such as mattresses, pillows, pillow slips and sheets had to be hired separately (as taste and means dictated) from appointed private trading contractors. The shops, restaurants and tourist garages (at Skukuza and Letaba) were also run by the contractors. At the end of 1955 the National Parks Board of Trustees assumed full responsibility for all its own trading and catering.

After the Second World War most rest camps had to be renovated (due to neglect during the war years) and progressively more conveniences were added to the huts. With the growth in tourist traffic and the necessity for more accommodation the authorites were faced with the dilemma of either building a number of smaller rest camps or enlarging existing rest camps where the required infrastructure had already been provided. The Board of Trustees opted for the second alternative.

In 1981 a major plan for the expansion of tourist facilities was approved by the Board of Trustees. This plan made provision for a number of medium-sized camps, and also endorsed the concept of smaller private rest camps, on the same lines as the Nwanedzi Rest Camp.

The popularity of the KNP as a tourist attraction is clearly illustrated in Table 1. Today the KNP has 18 rest camps, with a total of 3165 beds and 490 camping sites, providing for a maximum number of 6200 overnight visitors. In addition to the accommodation facilities there are also $787 \mathrm{~km}$ of tarred roads and $1255 \mathrm{~km}$ of gravel tourist roads. 
Table 1

The increase in tourist numbers at various intervals between 1928 and 1985

\begin{tabular}{cr}
\hline YEAR & TOTAL \\
\hline 1928 & 650 \\
1938 & 38014 \\
1948 & 58739 \\
$1959 / 60$ & 134759 \\
$1964 / 65$ & 247969 \\
$1969 / 70$ & 349710 \\
$1974 / 75$ & 363482 \\
$1979 / 80$ & 396653 \\
$1984 / 85$ & 509173 \\
\hline
\end{tabular}

In the development and expansion of the tourist facilities the major guiding principle has been to retain the natural attributes of the KNP as the major attraction of the area, and not to provide any amenities which would detract from the primary attraction.

\section{Administration}

At the time of the proclamation of the KNP (1926) a number of game ranger sections had been established. The primary functions of the game rangers were law enforcement and regular patrols through their sections to assess veld and water conditions and the distribution of animals.

Once the National Parks Board of Trustees had decided to institute tourism the responsibility of building rest camps and roads, which were virtually non-existent at the time, inevitably had to fall on the shoulders of the game rangers. In time the game rangers were even expected to issue permits, allocate accommodation and undertake various other chores in the running of the rest camps.

The above situation could not continue indefinitely and initially temporary artisans were employed to undertake some of the construction work, and permit issuers appointed in the rest camps. It was only towards the mid-1930s that a clerk was appointed to assist the Warden.

During the 1940 s and 1950 s various investigations, with subsequent recommendations, were made with regard to the administration of the Kruger National Park. It was during this period, and especially the late 1950s, that the administration made its greatest advances. A Tourist Manager was appointed, the Research Section and Information Section were established and a number of sub-sections of what currently comprise the Technical Services Section were created.

Through the years a number of changes have been made to the administration of the Kruger National Park. These led to its present composition: a Park Warden in charge of five sections, i.e. Wildlife Management, Tourism (and 
Trading), Technical Services, Liaison (Black Affairs) and the Flight Section. In addition, a Research and Information Section and a decentralised Administration Section are also permanently based in the Kruger National Park.

\section{Concluding Remarks}

The KNP is one of the largest national parks in the world. In stature it has even superseded the status of 'national park' and can justifiably stake its claim as an 'international park'. In spite of its sophisticated administration and the more than 0,5 million tourists who visit it each year, the major management objective of the area yet remains the maintenance of pristinity, the preservation of a characteristic aura and the wilderness experience in an ecosystem-orientated approach. Times, people, values and circumstances have changed but as fresh as ever remains the guiding philosophy of Stevenson-Hamilton (1946) in the management of the KNP, i.e. "Keep it simple, keep it wild"!

\section{BIBLIOGRAPHY}

*BRYNARD, A.M. 1972. Controlled burning in the Kruger National Parkhistory and development. Proc. Tall Timbers Fire Ecology Conf., 1971: Fire in Africa. Tall Timbers Research Station 11: 219-231.

*DE VOS, V., R.G. BENGIS and H.J. COETZEE. 1983. Population control of large mammals in the Kruger National Park. pp. 213-231. In: OWEN-SMITH, R.N. (ed.). Management of Large Mammals in African Conservation Areas. Pretoria: HAUM Educational Publishers.

GERTENBACH, W.P.D. 1980. Rainfall patterns in the Kruger National Park. Koedoe 23: 35-43.

GERTENBACH, W.P.D. 1983. Landscapes of the Kruger National Park. Koedoe 26: 9-121.

*GERTENBACH, W.P.D. 1983. Veld burning in the Kruger National Park: history, development, research and present policy. Internal Rep. to the National Parks Board of Trustees. (Unpubl.).

*JOUBERT, S.C.J. 1983. Managing threatened species in conservation areas. Proc. Int. Symp. on The Extinction Alternative. Endangered Wildlife Trust: 51-66.

*JOUBERT, S.C.J. 1983. A monitoring programme for an extensive national park. pp. 201-212. In: OWEN-SMITH, R.N. (ed.). Management of Large Mammals in African Conservation Areas. Pretoria: HAUM Educational Publishers.

PIENAAR, U. De V. 1958. Predator control policy. Internal Rep. to the National Parks Board of Trustees (Unpubl.).

PIENAAR, U. de V. 1969. Why elephant culling is necessary. African Wildlife 23 (3): 181-194.

*PIENAAR, U de V. 1969. Predator-prey relationships amongst the larger mammals of the Kruger National Park. Koedoe 12: 108-176.

*PIENAAR, U de V. 1970. The water resources of the Kruger National 
Park: past and present. African Wildlife 21 (4): 181-191.

*PIENAAR, U. de V. 1983. Management by intervention: the pragmatic/economic option. pp. 23-36. In: OWEN-SMITH, R.N. (ed.). Management of Large Mammals in African Conservation Areas. Pretoria: HAUM Educational Publishers.

PIENAAR, U. de V. 1985. Indications of progressive desiccation of the Transvaal Lowveld over the past 100 years, and implications for the water stabilization programme in the Kruger National Park. Koedoe 28: 93-165.

SANDENBERGH, J.A.B. 1947. The greatest handicap to game conservation in the Kruger National Park. Internal Rep. to the National Parks Board of Trustees. (Unpubl.).

STEVENSON-HAMILTON, J. 1906. Notes on the Sabi Game Reserve. Transactions of the Agricultural Journal: 603-617.

STEVENSON-HAMILTON, J. 1912. Annual Report of the Warden, Sabi and Shingwedzi Game Reserves. (Unpubl.).

STEVENSON-HAMILTON, J. 1937. South African Eden. London: Cassel. STEVENSON-HAMILTON, J. 1944. Annual Report of the Warden of the Kruger National Park. (Unpubl.).

STEVENSON-HAMILTON, J. 1946. Annual Report of the Warden of the Kruger National Park. (Unpubl.).

*STEVENSON-HAMILTON, J. 1949. The Lowveld: its Wildlife and its People. London: Cassel.

VAN DER SCHIJFF, H.P. 1957. Ekologiese studie van die flora van die Nasionale Krugerwildtuin. D. Sc. thesis, University of Potchefstroom for C.H.E., Potchefstroom.

*VAN WYK, P. 1972. Veld burning in the Kruger National Park. Proc. Tall Timbers Fire Ecology Conf., 1971: Fire in Africa. Tall Timbers Research Station 11: 9-32.

VERHOEF, J. 1986. Notes on archaeology and prehistoric mining in the Kruger National Park. Koedoe 29: 149-156.

* Are not cited in text but provide additional reading information. 